\title{
La región del Pacífico Mexicano en la Cuenca del Pacífico
}

$\mathrm{M}$ éxico, por su posición geográfica, ocupa un lugar privilegiado dentro de la Cuenca del Pacífico. La región del Pacífico Mexicano, incluye once de los treinta y dos estados que conforman la república mexicana. ${ }^{1}$ Con 867000 kilómetros cuadrados, la región posee 44 por ciento del territorio nacional y su longitud de línea de costa, de 7.8 miles de kilómetros, representa el 70 por ciento del total nacional. Por su extensión territorial, la región del Pacífico Mexicano es 2.6 veces mayor a Malasia, 2.29 veces el territorio de Japón, 6.9 veces el de Corea del Sur, 2.89 veces el de Filipinas y 1.69 veces el de Tailandia. En esta zona se concentran alrededor de 28 millones de mexicanos y más de una tercera parte de ellos habitan en zonas rurales, porcentaje superior al promedio nacional. Por el tamaño de su población, la región del Pacífico Mexicano es mayor a la correspondiente a Malasia y a Taiwan.

La región posee una dotación de tierra cultivable y de pastizal muy superior a la de los países del Pacífico Asiático, con excepción de la correspondiente a China e Indonesia. Así, los tres importadores netos de alimentos de el Pacífico Asiático, Japón, Corea del Sur y Taiwan, tienen en conjunto una dotación de tierra agrícola de 8.1 millones de hectáreas para alimentar a 191 millones de habitantes y, en contraste, en la región del Pacífico Mexicano, los estados de Jalisco y Michoacán poseen 8.3 millones de hectáreas de tierra agrícola.

La región del Pacífico Mexicano contribuye con aproximadamente una cuarta parte del PIB nacional. Por sectores, destaca la contribución de la zona al sector agropecuario, ya que aporta

* Investigadora y Jefa del Departamento de Estudios del Pacífico. Este artículo fue publicado en japonés en Jetro Sensor, December 2000, Japón, pp. 100 y 101 y es reproducido con permiso de los editores.

ORCID http://orcid.org/0000-0003-4926-0594
44 por ciento de la producción agrícola del país. En el sector industrial sobresalen la industria alimenticia, la de la madera, la textil y la de productos metálicos y maquinaria y equipo. La industria alimenticia regional contribuye con 27 por ciento del PIB sectorial a nivel nacional. En varios de los estados de la región, como Jalisco, Baja California y Sonora, se concentra la industria maquiladora del país, la cual está orientada sobre todo a la exportación. En este tipo de industria se concentra también la inversión extranjera directa que llega a México.

La participación de la región en el sector externo del país es también importante. Cabe destacar la participación de Jalisco, estado que genera una décima parte de la producción nacional y que ha contribuido notablemente al auge exportador de México en los últimos años. Con un nivel de exportaciones de $7.7 \mathrm{mil}$ millones de dólares en 1998, Jalisco participó con 6.6 por ciento de las exportaciones del país y con 9 por ciento de las importaciones nacionales. Este mismo auge exportador ha atraído la inversión extranjera directa (IED), la cual representa 7 por ciento de la IED que ha entrado al país en el período 1992-1998.

\section{Vínculos con Japón}

Por la cercanía geográfica, México tradicionalmente ha concentrado su comercio con Estados Unidos, mercado al que vende cerca de 85 por ciento de las exportaciones y del que obtiene alrededor de tres cuartas partes de las importaciones. Hasta ahora, en términos comerciales y de inversión, los vínculos de México con los países del Pacífico Asiático han sido débiles. No obstante, a partir del cambio de la estrategia económica mexicana de mediados de los ochenta, México ha abandonado el proteccionismo que lo caracterizaba y ha abierto sus puertas al exterior. Bajo esta nueva 
óptica México ya ha firmado 27 tratados de libre comercio con diferentes zonas y países del mundo. En este marco, las relaciones con Japón, que ha constituido para México el principal socio comercial en el Pacífico Asiático, cobran ahora mayor relevancia.

Para la región del Pacífico Mexicano, esta vinculación se torna ahora crucial. ¿Qué beneficios podrían obtener ambas partes de una relación más estrecha? Como se mencionó anteriormente, dos sectores descuellan por su relevancia en la región del Pacífico Mexicano: el sector agroindustrial y el sector de maquiladoras orientadas a la exportación. En ambos sectores, los dos países se complementan.

La región del Pacífico Mexicano se caracteriza por la producción de bienes agropecuarios que requieren del uso intensivo de mano de obra, como las frutas y hortalizas. Tres estados, Sinaloa, Michoacán y Oaxaca, producen un tercera parte de las hortalizas del país, y Chiapas, Michoacán y Sonora contribuyen con cuarenta por ciento de la producción de frutales, entre los que destacan productos exportables como el aguacate, el plátano, la naranja, el mango y la uva; sin contar con que Chiapas, al extremo sur, es el principal productor de café en México, que seguido por Oaxaca, producen en conjunto 60 por ciento del café mexicano. Es importante señalar el nuevo auge que se está imprimiendo en los estados del sur a la producción de productos agrícolas orgánicos, que son demandados cada vez más por el consumidor nipón. La región ya ha comenzado a atraer socios comerciales potenciales nipones. En estos días la visita una misión comercial de compradores de alimentos que incluye representantes de Jal Trading Inc., Marubeni Foods Corporation, Royal Co. Ltd, Nippi Trading Co. Ltd., Sowa Boeki Co y Global Fruit Co., que se entrevistaran con productores de los estados de Veracruz, Michoacán, Colima y Jalisco, los tres últimos ubicados en el Pacífico Mexicano.

La abundancia de mano de obra, la dotación de tierras aptas para estos cultivos y la experiencia exportadora de los estados ribereños del norte, constituyen oportunidades para que la región impulse las exportaciones agroalimentarias al Japón. Para este último país, por la escasez de mano de obra en el sector agrícola y la escasa dotación de recursos naturales, la producción agropecuaria mexicana constituye un complemento importante para la oferta interna alimentaria nipona. Es necesario destacar que a partir de los ochenta las importaciones niponas de frutas y hortalizas han tendido a incrementarse. Estas importaciones se han visto impulsadas por varios factores tales como el cambio de la dieta alimenticia de los nipones al elevarse su nivel de ingreso; la mayor participación de la mujer en la fuerza de trabajo $\mathrm{y}$, vinculado a esto, el crecimiento de la industria restaurantera $y$, la venta de alimentos procesados. También ha contribuido a ello la desregulación del sector de distribución en Japón.

Cabe destacar que en 1992 en México se modificó el régimen de tenencia de la tierra que prevalecía desde 1917. Con esta modificación, ahora es factible que llegue la inversión extranjera al campo mexicano y ello ofrece posibilidades de co-inversiones con productores agrícolas mexicanos.

En el caso del sector maquilador sobresale el de la industria electrónica. Los productos electrónicos constituyen 32 por ciento de las exportaciones manufactureras mexicanas y, de éstas, la mitad corresponde al sector maquilador. El subsector de eléctricos y electrónicos constituye 27 por ciento de las plantas maquiladoras y es una fuente importante de empleo al absorber 37 por ciento de la mano de obra de la industria maquiladora. Dos son las características principales de la industria electrónica en México: los altos niveles de inversión extranjera y la concentración geográfica en dos ciudades: Guadalajara y Tijuana, ambas situadas en la región del Pacífico Mexicano. La concentración en Tijuana obedece a su cercanía con el mercado consumidor norteamericano. El auge de la industria maquiladora en Tijuana se dio a partir de 19871989, que coincidió con el apogeo de la ubicación de transnacionales japonesas fuera de Japón por 
la revaluación del yen. La mayoría de las empresas japonesas producen equipo eléctrico y electrónico y electrodomésticos. Es una característica general de la empresa maquiladora en México que presente un alto contenido importado en sus productos finales. Así, más de la mitad de los países abastecedores de la maquiladora japonesa en Tijuana se ubican en Asia, siendo los principales proveedores, los nipones.

En Guadalajara, situada en el centro de la región del Pacífico Mexicano, son factores de atracción la estratégica posición geográfica de ésta en el occidente del país; lo bien conectada que está la ciudad tanto a los mercados del interior del país como a los del exterior; la oferta de mano de obra calificada que compite en salarios con el norte; el papel activo del gobierno estatal en atraer inversión extranjera, así como también el buen clima. En 1999, 73 por ciento de las exportaciones de Jalisco provinieron de la industria electrónica y 40 por ciento de la inversión nacional y extranjera se concentró en ese sector. Jalisco presenta una menor concentración de mercados comparado a nivel nacional: 70 por ciento de las ventas al exterior son a Estados Unidos; 12 por ciento a la Unión Europea y 9 por ciento a Asia. De esta última región importa también alrededor de 9 por ciento. En el llamado "Valle del Silicio Mexicano" se ubican cinco de las empresas transnacionales manufactureras más importantes: SCI Systems, Flextronics, Solectron, Jabil Circuit y Nat Steel Electronics, las que generan una importante demanda de empleo y contribuyen con la mayor parte de la producción de computadoras en México.

Cabe hacer notar que a partir de enero de 2001, dentro del marco del Tratado de Libre Comercio con América del Norte (TLCAN), concluye el privilegio que México concede a las maquiladoras de importar insumos libres de impuestos. Esta nueva disposición podría tener el efecto de retraer la inversión extranjera en este tipo de industria o bien podría estimular el establecimiento de proveedores externos en territorio mexicano.

Con el nuevo tratado de libre comercio propuesto entre México y Japón, la industria maquiladora electrónica ofrece beneficios mutuos para ambos países en general y para la región del Pacífico Mexicano en particular. Reglas más favorables para la inversión nipona en México podrían incrementar los flujos de inversión en la región, generando con ello: a) en México, en el corto plazo, mayor empleo y auge exportador y, en el largo plazo, la incorporación de mayor valor agregado en los productos y un mayor encadenamiento con las pequeñas y medianas empresas mexicanas, que hasta ahora han estado excluidas del auge exportador, y b) para Japón representaría una oportunidad de aprovechar la apertura de México para constituir en ella una plataforma de exportación y penetrar más fácilmente los mercados al norte y sur de la frontera mexicana.

Así, por la dotación de recursos naturales, de recursos humanos y por la posición geográfica, la región del Pacífico Mexicano se perfila como una zona de gran importancia para impulsar y estrechar los vínculos económicos, sociales y culturales con la región del Pacífico Asiático en general y con Japón en particular. Por la especialización que tiene la región actualmente en las actividades agropecuarias y agroindustriales, así como por la fuerte inversión extranjera en la industria maquiladora, estos sectores presentan fuertes ventajas dentro de la inserción de la región en la Cuenca del Pacífico al tiempo que también ofrece oportunidades para sus socios al otro lado del Pacífico y en especial para Japón, que ha sido tradicionalmente su socio más cercano. 


\section{$E$ cos de A sia en M éxico}

\section{Nota}

1 La región incluye, de norte a sur, los estados de Baja California, Baja California Sur, Sonora, Sinaloa, Nayarit, Jalisco, Colima, Michoacán, Guerrero, Oaxaca y Chiapas.

\section{Fuentes}

a) Revista de Comercio Exterior, Bancomext, vol. 49, números 9 y 10 de septiembre y octubre de 1999, respectivamente. Ambas están dedicadas a la industria maquiladora. b) INEGI, banco de datos internet. c) Banco de México, Informes económicos, varios números. d) Sistema Estatal de Información de Jalisco, SEIJAL, varias publicaciones. e) Excelsior. T!: 